\title{
Model for Design of Portfolio Venture Investment Contract When Taking Moral Hazards into Account
}

\author{
L. Yin, ${ }^{1}$ Y. Liu $\mathbb{D},{ }^{2}$ and Z. Wang ${ }^{2}$ \\ ${ }^{1}$ School of Financial Technology, Shanghai Lixin University of Accounting and Finance, Shanghai 201209, China \\ ${ }^{2}$ School of Management, Wuhan University of Technology, Wuhan 430070, China \\ Correspondence should be addressed to Y. Liu; liuying@whut.edu.cn
}

Received 10 June 2020; Revised 28 June 2020; Accepted 3 July 2020; Published 25 August 2020

Academic Editor: Lu Zhen

Copyright (c) 2020 L. Yin et al. This is an open access article distributed under the Creative Commons Attribution License, which permits unrestricted use, distribution, and reproduction in any medium, provided the original work is properly cited.

Portfolio investment is adopted by the venture capital to diversify those risks involved in project selection, investing or operating so that the venture capitalist can expect a relatively stable income and lower financing risks. Based on the design of portfolio investment contract with unlimited funds developed by Kanniainen and Keuschnigg, and Inderst et al., this article makes a modification and presents a model given the limitation of funds available for the venture capitalist. It is demonstrated that the marginal benefit of efforts paid by the entrepreneurs exceeds the marginal cost, given the limitation of funds available, which will conduce to a high-level engagement of the entrepreneurs. Thus, by adopting the design of renegotiation contract, the venture capitalist can manage to stimulate the entrepreneurs to make efforts, which is to result in moral hazard reduction.

\section{Introduction}

Enhanced risks in the venture capital investments may vary due to influences of the internal and external environment. The high uncertainty makes it essential for the venture capital to adopt an appropriate portfolio investment. It is intended to spread and diversify risks and in turn to ensure a high average yield on the investments. This is especially true with the high-tech investments. Generally, the venture capital should be invested in different regions, industries, companies, or projects instead of investing in a single one. By this means, losses from the failed investments can be made up for by the yields from those succeeded. For the venture capital investments of high uncertainty, adoption of a portfolio is becoming the choice of most venture capitalist.

By diversifying the risks involved in the project selection, investing, or operating, portfolio investments ensure the venture capitalist a relatively stable income and lower financing risks. Usually, in addition to making up for the losses resulted from the failed projects accounting for up to $70 \%$ of the number of assets included in a portfolio, the yields generated by the other $30 \%$ succeeded can bring the venture capitalist a return high enough.
In the US, the venture capital is typically invested in a dozen and even dozens of projects. Generally, the venture capitalist is not the only controlling party. They usually account for $10 \%-30 \%$ of the invested firm's total shares. According to a survey made in 2002 covering 218 venture projects of the US, a total loss was reported for $14.7 \%$ of all the projects and partial loss for $24.8 \%$. However, of all the 218 projects, up to $60 \%$ earned a return of over $100 \%$. According to the statistics, over the preceding dozens of years, the venture capital investments have produced an average yield of approximately $25 \%$, which is far more than other types of investments. Adoption of portfolio investment contributes much to this high yield within a stable context of contracts.

The venture investments are characterized as risky and high yielding. Instead of merely taking risks, the venture capitalist always tries his best to lower the potential risks. To achieve this, most times, a portfolio is set up. Success of a venture firm is the result of the efforts made by both capitalist and entrepreneur. Even for one single asset venture investment, some moral hazard can arise from the information asymmetry between the capitalist and entrepreneur and the resulted lack of efforts. Obviously, in the context of a 
portfolio the moral hazard problem associated is just more complex. It is necessary to figure out an appropriate design of portfolio contract for the purpose of avoiding moral hazard risk related to portfolio investments.

This research is intended to contribute to the findings of what makes an appropriate design of portfolio contract. Either from a theoretic perspective or a practical one, the portfolio investment decision is more likely to be constrained by limited fund availability to the venture capitalist. Taking this fund availability constraint into account, our article develops a model for the design of the portfolio venture investment contract, by which means an insight can be got into the underlying mechanism and how it works on bilateral moral hazard reduction.

\section{Literature Review}

With a portfolio investment contract, the venture capitalist invests in many ventures simultaneously, which gives rise to the information asymmetry between the investor and each entrepreneur and the resulted moral hazard. Study on this type of moral hazard problem can trace back to that emerges between one principal and multiple agents. Holmstrom [1] conducted the earliest study on the moral hazard problem arising from the information asymmetry between one principal and multiple agents. He concluded that when the efforts made by each agent cannot be observed by the principal and subsequently each one's contribution to the outcome cannot be identified, the agents will not try their best. Instead, they may take advantage of information asymmetry and behave as a free rider.

When a venture investment contract involves two or more entrepreneurs, information about the efforts made by each is usually unavailable. It is hard if it is not impossible to identify the contribution made by each one to the outcome specifically. As a result, moral hazard problem and its negative results can be expected. Therefore, a good design of portfolio investment contract should conduce to avoiding or reducing moral hazard between the one principal and multiple agents.

Kaplan et al. [2,3] explored how the lack of efforts occurs when the venture capitalist, as the principal, interacts with two entrepreneurs (the agents) given complete information or incomplete information. It is suggested that moral hazard may arise in case the agents conspire with each other to undermine the venture investor's interests, or otherwise, one of the agents conspires with the principal and damages the interests of the other.

Cestone [4] concluded that, for a portfolio investment comprising two venture firms, the value of the ventures is positively related to the abilities of both the venture capitalist and the entrepreneur in charge, as well as their efforts. Additionally, the author presented an optimal income allocation plan to motivate both sides and eliminate the bilateral moral hazard.

Other research studies on moral hazard associated with the portfolio contract include figuring out the optimal number of the venture projects invested (or in other words, deciding on an optimal scale for the portfolio in question) given a certain level of efforts to be paid by all stakeholders.
Kanniainen and Keuschnigg [5], from the perspective of the bilateral moral hazard problem emerging between the venture capitalist and entrepreneur, analyzed theoretically how the capitalist should determine an optimal number of the start-up firms included in a portfolio investment. They hold that there is a trade-off between the number of start-up firms and the amount of assistance the capitalist could grant to each firm. That is, the more investees the less assistance to each. Such a trade-off determines there exist an optimal scale for a portfolio venture investment. Furthermore, they gave an interpretation about why only limited number of venture projects can be included in a portfolio investment when aimed at an optimal yield level totally. It was also supposed that as the investees increase and the assistance granted to each venture firm decreases, the entrepreneur would require more return from his/her firm. Bengtsson and Sensoy [6] investigated how contract design is related to $\mathrm{VC}$ abilities to monitor and provide value-added services to the entrepreneur and found that previous estimates of the amount entrepreneurs pay for affiliation with high-quality VCs are overstated.

Khanna and Mathews [7] tried to figure out the number of start-up firms to be invested based on the extent to which the venture capitalist can provide each firm with consultancy services. They believed there exist a reasonable and balanced level of the consultancy services each venture firm can expect and of the portfolio scale. Having referred to the research studies by Kanniainen et al. [5, 8], Khanna and Mathews argued that it is not enough to determine a portfolio scale merely based on finding the equilibrium of portfolio scale and the upper limit for services each firm may expect. Instead, they argued that the optimal portfolio scale can be reasonably determined only when the abilities of the venture capitalist are taken into account and the intensity of consultancy services each firm can have is predictable. Other similar research studies include that by $\mathrm{He}$ [9], Hori and Osano [10], Lin [11], Fu et al. [12], and An and Schneider [13]. They conducted studies on the equilibrium of efforts allocation among the venture investees and portfolio scale from different perspectives and tried to summarize the mechanism underlying a portfolio investment contract motivating the entrepreneurs. Chernenko et al. [14] found that having to carefully manage their own liquidity pushes mutual funds to require stronger redemption rights, suggesting contractual choices consistent with mutual funds' short-term capital sources. Burchardt et al. [15] provided a comprehensive theoretical and empirical literature review of venture capital contracts and highlighted the major discrepancies between theory and practice.

In brief, it can be concluded from the above literature that when bounded by a portfolio investment contract, both the capitalist and the entrepreneurs have to make efforts. It is especially true with the former. For the venture capitalist, reasonable allocation of the limited consultancy services that he/she is able to offer among the investees is critical to yield maximization. With the value-added services the capitalist has to provide being taken into account, he/she has to balance the more yields brought by a larger size of portfolio against the limitation of his/her ability to deliver valueadded services. 
Overall, how much effort would both the capitalist and each of the entrepreneurs like to make is critical to development of the start-up firms, especially in the framework of a portfolio investment contract. Since portfolio investment involves multiple entrepreneurs, the venture capitalist is faced with a more complex situation and it is more important to decide on a reasonable allocation of efforts. Portfolio investment has become an increasingly important means to invest in the start-up firms. The design of portfolio contract needs to be analyzed so that an optimal level of efforts be ensured from mechanisms. Based on the previous research studies, this article develops a model to optimize the design of portfolio investment contract which is expected to reach an equilibrium of incentives for the venture capitalist and each of the entrepreneurs. With this design adopted, moral hazards can be reduced and both sides can be stimulated to make essential efforts.

Also, it can be seen that, on the basis of the work involving just one entrepreneur, some researchers analyzed the possible means by which the capitalist can urge more entrepreneurs to make efforts and reduce the bilateral moral hazards in terms of portfolio investment contract. They assumed that, with unlimited availability of funds, the capitalist has enough money to make a second invest in both start-up firms. Thus, no one will fail to get further invested. That means, without fund constraint, the two start-ups do not have to compete with each other. However, that is usually not the truth. The portfolio investment decision is actually more likely to be constrained by limited fund availability to the venture capitalist. So, this article makes a modification. It is supposed that the decision about a second investment is constrained by limited fund availability to the venture capitalist. In this case, the entrepreneurs involved in the portfolio contract have to compete with each other to obtain the second investment.

\section{Model Introduction}

Consider a case of investing in multiple venture firms simultaneously. Each firm has a project which needs management assistance from the capitalist. A four-stage model will be developed for the venture investment contract.

Suppose each start-up project is to be invested in twice. The first investment amounts to I_1 and the second I_2. After the first investment, both venture capitalist and entrepreneurs can observe the immediate state of the project which is relied upon to make a decision on whether to make a second investment. The whole process can be divided into four stages, which is demonstrated in Figure 1.

The logics underlying this four-stage model is that, in reality, most venture investment contracts cannot provide that the fund needs be satisfied once and for all. What is more reasonable and more usual in venture investment practices is to have a shot, wait to see the result, and then decide. With this in mind, we make the assumption that the venture capitalist will invest an amount necessary to get through the beginning phase of the selected venture projects. Then, the entrepreneurs are engaged in operating their startups and achieve some result based on which the capitalist is to make the decision about whether to continue with investment. Once a further-investment decision is made, a renegotiation will be settled and the reinvestment contract is decided on. After this second investment, any yields of the start-up project will be allocated between the capitalist and the entrepreneur according to what is specified in the contract. This process can be logically simplified as the fourphase model shown in Figure 1.

Stage 1: sign the initial investment contract. With no loss of generality, assume that one venture capitalist invests in two start-ups. The amounts initially invested are both $I_{1}$. As a return, the capitalist owns shares of two start-ups. Start-up firm $i$ has shares amounted to $s_{i}$, $i=1,2$.

Stage 2: after the initial investment, each of the two entrepreneurs is engaged in operating his/her start-up. The extent to which the entrepreneur would be engaged depends on the firm's state following the initial investment, $\theta$. After the initial investment, the entrepreneurs take up their line of duties. Assume that an entrepreneur may choose to have a high or low level of engagement. This level of engagement is denoted as e, $e \in\left\{e_{h}, e_{l}\right\}$. Costs will be incurred under different levels of engagement, which are denoted as $C\left(e_{h}\right)$ and $C\left(e_{l}\right)$. It is specified that $C\left(e_{h}\right)>C\left(e_{l}\right)$. And the marginal cost of level of engagement is $\Delta C, \Delta C=C\left(e_{h}\right)-C\left(e_{l}\right)$. Suppose that the extent to which the entrepreneur is engaged determines the probability that the firm falls in a certain state. The entrepreneur makes efforts, the firm can have one of the two states, $\left\{\theta_{g}, \theta_{m}\right\}$, and $\theta_{g}$ and $\theta_{m}$ represent the good state and the normal state, respectively. When the entrepreneur is highly engaged, the start-up has the good state $\left(\theta_{g}\right)$ with probability of $q_{h}$, or the normal state $\left(\theta_{m}\right)$ with $\left(1-q_{h}\right)$. If the entrepreneur takes a low level of engagement, the start-up has the good state $\left(\theta_{g}\right)$ with probability of $q_{l}$, or the normal state $\left(\theta_{m}\right)$ with $\left(1-q_{l}\right)$. It is believed that $1>q_{h}>q_{l}>0$.

Stage 3: based on the observed state of the start-up, $\theta$, the venture capitalist renegotiates with each of the entrepreneurs to determine whether to make a second investment and how to reallocate the income between the two sides. The total yield of each venture project can be $\prod$ or 0 . The probability of being $\prod$ or 0 is dependent on the efforts made by the entrepreneur as well as the reinvestment decision made by the capitalist. If the capitalist, based on the observed state $(\theta)$, chooses to quit, the start-up will achieve the yield of $\prod$ with a much smaller probability due to the absence of further investment and assistance from the capitalist. This low probability is denoted as $P_{0}$. And the probability of having no yield is $\left(1-P_{0}\right)$. Obviously, the expected income with no further investment from the capitalist can be computed as

$$
R_{0}=P_{0} \cdot \prod
$$

If the venture capitalist chooses to make a second investment, the start-up will achieve the yield of $\prod$ with a 


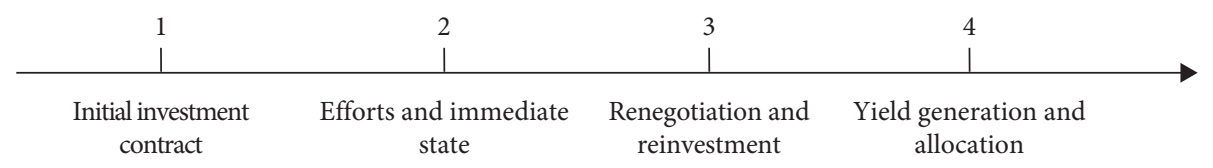

FIGURE 1: Sequence of the game involved in a portfolio investment contract.

larger probability. In the case that $\theta_{g}$ is observed with the project, the probability of achieving $\prod$ is $P_{g}$ and no yield $\left(1-P_{g}\right)$. In the case of $\theta_{m}$, the probability of having $\prod$ is $P_{m}$ and no yield $\left(1-P_{m}\right)$. It is no surprise that the expected total yield with the state $\theta_{g}$ is more than that with $\theta_{m}$, and the expected total yield with further investment is more than that with no more. So, it is stated that $P_{g}>P_{m}>P_{0}$. Apparently, when $\theta_{g}$ is observed with the start-up, the expected income can be calculated as

$$
R_{g}=P_{g} \cdot \prod \text {. }
$$

When $\theta_{m}$ is observed, the expected income is

$$
R_{m}=P_{m} \cdot \prod \text {. }
$$

Assume the additional investment is $I_{2}$. Provided that the start-up receives further investment, the marginal income is $r_{g}$ with the observed state of $\theta_{g}$ or $r_{m}$ with $\theta_{m}$. Then,

$$
\begin{aligned}
& r_{g}=R_{g}-R_{0}-I_{2}, \\
& r_{m}=R_{m}-R_{0}-I_{2} .
\end{aligned}
$$

If $r_{g}>r_{m}>0$, that is, there is a positive marginal income of further investment whether the observed state is $\theta_{g}$ or $r_{m}$. Therefore, further investment is always profitable.

The venture capitalist and each entrepreneur would renegotiate based on the observed firm state and the total yield expectation. By renegotiation of income allocation and redesign of investment contract, the capitalist manages to urge the entrepreneur to make efforts in Stage 2 so that the venture investment can be continued.

Stage 4: the expected yield having been earned, income is allocated between the capitalist and each entrepreneur. After the venture project has achieved the expected earnings, the capitalist and the entrepreneur will have earnings allocated according to the agreement reached in advance. It is assumed that the marginal income of efforts made by the entrepreneur exceeds the marginal cost. So, a rational entrepreneur would be highly engaged.

When the entrepreneur is indeed highly engaged, the start-up will have a state following the initial investment of $\theta_{g}$ with a probability of $q_{h}$, or $\theta_{m}$ with $\left(1-q_{h}\right)$. Then, the expected marginal income of a second investment is

$$
q_{h} \cdot r_{g}+\left(1-q_{h}\right) \cdot r_{m}
$$

Or if the entrepreneur is not so highly engaged, the startup will have a state following the initial investment of $\theta_{g}$ with a probability of $q_{l}$, or $\theta_{m}$ with $\left(1-q_{l}\right)$. Then, the expected marginal income of further investment is

$$
q_{l} \cdot r_{g}+\left(1-q_{l}\right) \cdot r_{m}
$$

The entrepreneur will be urged to be highly engaged only when the marginal income of further investment with a high level of engagement is no less than that with a low level combined with the marginal cost of efforts made. That is,

$$
q_{h} \cdot r_{g}+\left(1-q_{h}\right) \cdot r_{m} \geq q_{l} \cdot r_{g}+\left(1-q_{l}\right) \cdot r_{m}+\Delta C
$$

which can be reduced as

$$
\left(q_{h}-q_{l}\right) \cdot\left(r_{g}-r_{m}\right) \geq \Delta C
$$

Equation (9) gives the constraints that ensure a high level of engagement by the entrepreneur.

3.1. Design of Portfolio Investment Contract Given the Limitation of Funds. Constrained by limited fund availability, the venture capitalist invests $I_{1}$ in each start-up initially, and after a certain period of time, there is only $I_{2}$ available for a second investment. That means, this capitalist manages to raise funds totaling $\left(2 I_{1}+I_{2}\right)$. Having invested $I_{1}$ in each of two start-ups, the capitalist has to choose the one more competitive to make further investment. Evidently, the observed state of each start-up determines which one will get a second investment. The one seeming more competitive wins.

As supposed earlier, a start-up can have the state of $\theta_{g}$ or $\theta_{m}$ after the initial investment. When the two investees have different states, one $\theta_{g}$ and the other $\theta_{m}$, the venture capitalist would like to invest another $I_{2}$ in the one demonstrating $\theta_{g}$. If both of the two have the state of $\theta_{g}$, or both $\theta_{m}$, the capitalist will invest $I_{2}$ in one of the two with equal probability.

With no loss of generality, assume Start-up 1 demonstrates $\theta_{g}$ after the initial investment and Start-up $2 \theta_{m}$. In this case, Start-up 1 will receive further investment and Start-up 2 will not have a chance. According to the renegotiation scheme of income allocation, Start-up 1 will have earnings of $\left(s_{1} \cdot R_{0}+\rho \cdot r_{g}\right)$, where $\rho$ is the shares Start-up 1 owns based on the design of reinvestment contract. On the contrary, Start-up 2 will earn $s_{2} \cdot R_{0}$.

In the case that the two start-ups both demonstrate the state of $\theta_{g}$ or otherwise $\theta_{m}$, the capitalist will make further invest in any of them randomly. Then, Start-up 1 will have earnings of $\left(s_{1} \cdot R_{0}+(1 / 2) \rho \cdot r\right)$, and Start-up 2 will earn $\left(s_{1} \cdot R_{0}+(1 / 2) \rho \cdot r\right)$, where $r=\left\{r_{g}, r_{m}\right\}$.

From the perspective of Start-up 1, since Start-up 1 itself and Start-up 2 may decide to have a high or low level of engagement, the yield Start-up 1 can expect varies. It is analyzed as follows.

A Nash equilibrium exists, as demonstrated in Figure 2, when the two start-ups make their choices about how much 


\begin{tabular}{|c|c|c|c|}
\hline & \multicolumn{2}{|c|}{ Start-up 2} \\
\hline & & $\begin{array}{l}\text { Highly } \\
\text { engaged }\end{array}$ & $\begin{array}{c}\text { Lowly } \\
\text { engaged }\end{array}$ \\
\hline \multirow{2}{*}{ Start-up 1} & $\begin{array}{l}\text { Highly } \\
\text { engaged }\end{array}$ & $\left(U_{1_{a}}, U_{2_{a}}\right)$ & $\left(U_{1_{b}}, U_{2_{b}}\right)$ \\
\hline & $\begin{array}{c}\text { Lowly } \\
\text { engaged }\end{array}$ & $\left(U_{1_{d}}, U_{2_{d}}\right)$ & $\left(U_{1_{c}}, U_{2_{c}}\right)$ \\
\hline
\end{tabular}

FIgURE 2: Expected income under different strategy combinations.

effort to make. $U_{i j}(i=\{1,2\}, j=\{a, b, c, d\})$ is the yield that Start-up 1 can expect when the strategy combination adopted by entrepreneurs is $j(a, b, c$ or $d)$, as shown in Figure 2.

3.2. The Case That Entrepreneur 2 Chooses to Be Highly Engaged. In this case, when Entrepreneur 1 also chooses to be highly engaged, Start-up 1 may earn $\left(s_{1} \cdot R_{0}+\rho \cdot r_{g}\right)$ or $s_{1} \cdot R_{0}$ with equal probability of $q_{h} \cdot\left(1-q_{h}\right)$, or earn $\left(s_{1}\right.$. $\left.R_{0}+(1 / 2) \rho \cdot r_{g}\right)$ with probability of $q_{h} \cdot q_{h}$, or $\left(s_{1} \cdot R_{0}+\right.$ $\left.(1 / 2) \rho \cdot r_{m}\right)$ with $\left(1-q_{h}\right) \cdot\left(1-q_{h}\right)$. So, the expected yield of Start-up 1 when Entrepreneur 1 is highly engaged is

$$
\begin{aligned}
U_{1_{a}}= & q_{h}\left(1-q_{h}\right)\left(s_{1} \cdot R_{0}+\rho \cdot r_{g}\right)+q_{h}\left(1-q_{h}\right)\left(s_{1} \cdot R_{0}\right) \\
& +q_{h}^{2}\left(s_{1} \cdot R_{0}+\frac{1}{2} \rho \cdot r_{g}\right)+\left(1-q_{h}\right)^{2}\left(s_{1} \cdot R_{0}+\frac{1}{2} \rho \cdot r_{m}\right),
\end{aligned}
$$

which can be reduced as

$$
U_{1_{a}}=s_{1} \cdot R_{0}+\rho \cdot r_{g} \cdot\left(q_{h}-\frac{1}{2} q_{h}^{2}\right)+\frac{1}{2} \rho \cdot r_{m} \cdot\left(1-2 q_{h}+q_{h}^{2}\right) .
$$

If otherwise (i.e., Entrepreneur 1 demonstrates a low level of engagement), Start-up 1 may earn $\left(s_{1} \cdot R_{0}+\rho \cdot r_{q}\right)$ with probability of $q_{l} \cdot\left(1-q_{h}\right)$, or earn $s_{1} \cdot R_{0}$ with probability of $q_{h} \cdot\left(1-q_{l}\right)$, or $\left(s_{1} \cdot R_{0}+(1 / 2) \rho \cdot r_{g}\right)$ with $q_{l} \cdot q_{h}$, or $\left(s_{1} \cdot R_{0}+(1 / 2) \rho \cdot r_{m}\right)$ with $\left(1-q_{l}\right) \cdot\left(1-q_{h}\right)$. So, the expected yield of Start-up 1 if Entrepreneur 1 is lowly engaged is

$$
\begin{aligned}
U_{1_{d}}= & q_{l}\left(1-q_{h}\right)\left(s_{1} \cdot R_{0}+\rho \cdot r_{g}\right)+q_{h}\left(1-q_{l}\right)\left(s_{1} \cdot R_{0}\right) \\
& +q_{l} \cdot q_{h}\left(s_{1} \cdot R_{0}+\frac{1}{2} \rho \cdot r_{g}\right) \\
& +\left(1-q_{l}\right)\left(1-q_{h}\right)\left(s_{1} \cdot R_{0}+\frac{1}{2} \rho \cdot r_{m}\right),
\end{aligned}
$$

which can be reduced as

$$
\begin{aligned}
U_{1_{d}}= & s_{1} \cdot R_{0}+\rho \cdot r_{g} \cdot\left(q_{l}-\frac{1}{2} q_{l} q_{h}\right) \\
& +\frac{1}{2} \rho \cdot r_{m} \cdot\left(1-q_{l}-q_{h}+q_{l} q_{h}\right) .
\end{aligned}
$$

To ensure that moral hazard be eliminated and Entrepreneur 1 choose to be highly engaged, the capitalist has to make sure that Entrepreneur 1 will earn more only when he/ she makes more efforts. So, equation (14) holds.

$$
U_{1_{a}}-U_{1_{d}} \geq \Delta C \text {. }
$$

Integrate equations (11), (13), and (14), and we obtain

$$
\rho\left(q_{h}-q_{l}\right)\left\{\left(r_{g}-r_{m}\right)+\frac{1}{2}\left[r_{m}-q_{h}\left(r_{g}-r_{m}\right)\right]\right\} \geq \Delta C \text {. }
$$

The case that Entrepreneur 2 chooses to be is lowly engaged.

As analyzed in Case (1), the expected yield of Start-up 1 when Entrepreneur 1 chooses to be highly engaged is

$$
\begin{aligned}
U_{1_{b}}= & s_{1} \cdot R_{0}+\rho \cdot r_{g} \cdot\left(q_{h}-\frac{1}{2} q_{h} q_{l}\right) \\
& +\frac{1}{2} \rho \cdot r_{m} \cdot\left(1-q_{h}-q_{l}+q_{l}^{2}\right) .
\end{aligned}
$$

The expected yield of Start-up 1 if Entrepreneur 1 is lowly engaged is

$$
U_{1_{c}}=s_{1} \cdot R_{0}+\rho \cdot r_{g} \cdot\left(q_{l}-\frac{1}{2} q_{l}^{2}\right)+\frac{1}{2} \rho \cdot r_{m} \cdot\left(1-2 q_{l}+q_{l}^{2}\right) .
$$

The constraint that ensures a high level of engagement by Entrepreneur 1 is

$$
\rho\left(q_{h}-q_{l}\right)\left\{\left(r_{g}-r_{m}\right)+\frac{1}{2}\left[r_{m}-q_{l}\left(r_{g}-r_{m}\right)\right]\right\} \geq \Delta C .
$$

As long as equations (15) and (18) hold true, Entrepreneur 1 would always take a high level of engagement to maximize his/her earnings. With this in mind, the venture capitalist, by designing the renegotiation contract, can manage to urge Entrepreneur 1 to make efforts and reduce moral hazards.

The discussion about Entrepreneur 1 can be safely generalized to Entrepreneur 2, since Entrepreneur 1 is just one picked out at random. So, the conclusion we draw for Entrepreneur 1 is completely adaptable to Entrepreneur 2.

It can be seen that constrained by the portfolio investment contract given limitation of funds, the entrepreneurs have to compete with each other for a second investment. And provided that the portfolio investment has unlimited availability of funds, the entrepreneurs can be hardly motivated due to the lack of competition. The constraint from fund availability gives rise to an increase of marginal income of efforts made. Therefore, a portfolio investment contract with limited availability of funds can urge the entrepreneurs to be highly engaged by bringing in competitive stimulation mechanism.

\section{Conclusions}

In the context of portfolio investment contract, the problem concerning the principal and agents motivation gets more complex because of more stakeholders involved. More diversified moral hazards arising also require more complicated design of the portfolio contract. The information 
asymmetry makes either the venture capitalist or the entrepreneurs can hardly identify the engagement level of the counterpart or the resulted contributions. And, it is even harder to figure out the allocation of efforts by the capitalist among different venture projects included in a portfolio investment contract.

Kanniainen and Keuschnigg [5] and Bengtsson and Sensoy [6], based on research studies on one entrepreneur motivation, analyzed the possible means by which the capitalist can urge more entrepreneurs to make efforts and reduce the bilateral moral hazards in terms of portfolio investment contract. They assumed that, with unlimited availability of funds, the capitalist has enough money to make a second investment in both start-up firms. Thus, no one will fail to get further invested. That means, without fund constraint, the two start-ups do not have to compete with each other. Instead, both of them can get the second investment by renegotiating with the capitalist about income allocation.

A modification is made in this article. It is supposed that the decision about a second investment is constrained by limited fund availability to the venture capitalist. In this case, the entrepreneurs involved in the portfolio contract have to compete with each other to obtain the second investment. The constraint from fund availability gives rise to an increase of marginal income of efforts made. Therefore, a portfolio contract with limited availability of funds can urge the entrepreneurs to be highly engaged by bringing in competitive stimulation mechanism. It is demonstrated that the marginal benefit of efforts paid by the entrepreneurs exceeds the marginal cost, given the limitation of funds available, which will conduce to a high-level engagement of the entrepreneurs. Thus, by adopting the design of renegotiation contract, the venture capitalist can manage to stimulate the entrepreneurs to make efforts, which is to result in moral hazard reduction.

This research contributes to extension of those pioneered by Kanniainen and Keuschnigg and some other scholars [5]. Either from a theoretic perspective or a practical one, the portfolio investment decision is more likely to be constrained by limited fund availability to the venture capitalist. Taking this fund availability constraint into account, our article develops a model for design of the portfolio venture investment contract, which is intended to get an insight into the underlying mechanism and how it works on bilateral moral hazard reduction. Thus, this article contributes to the venture capital finance literature.

One drawback of this research is the lack of comparative analysis of the outcomes provided limitation and no limitation of funds available. Compared with that of unlimited fund availability, how big a marginal effect can the stimulation have that a portfolio contract with limitation of funds imposes on the entrepreneurs. In addition, constrained by limited fund availability, the capitalist has to choose only one of the initially invested venture firms to make further investment at the cost of losing the other, which is likely to inspire the capitalist to contribute more in the selected venture firm development. And the benefits this inspiration effect on the capitalist brings about are also ignored in this article. A comparative analysis and the equilibrium issue involved will be the focus of further research studies.

\section{Data Availability}

No data are required to support the findings of this study.

\section{Conflicts of Interest}

The authors declare that there are no conflicts of interest regarding the publication of this paper.

\section{References}

[1] B. Holmstrom, "Moral hazard in teams," The Bell Journal of Economics, vol. 13, no. 2, pp. 324-340, 1982.

[2] S. N. Kaplan and P. Strömberg, "Characteristics, contracts, and actions: evidence from venture capitalist analyses," The Journal of Finance, vol. 59, no. 5, pp. 2177-2210, 2004.

[3] E. Ball, H. H. Chiu, and R. Smith, "Can VCs time the market? An analysis of exit choice for venture-backed firms," Review of Financial Studies, vol. 24, no. 9, pp. 3105-3138, 2011.

[4] G. Cestone, "Venture capital meets contract theory: risky claims or formal control?" Review of Finance, vol. 18, 2001.

[5] V. Kanniainen and C. Keuschnigg, "The optimal portfolio of start-up firms in venture capital finance," Journal of Corporate Finance, vol. 9, no. 5, pp. 521-534, 2000.

[6] O. Bengtsson and B. Sensoy, "Investor abilities and financial contracting: evidence from venture capital," Journal of Financial Intermediation, vol. 20, no. 4, pp. 477-502, 2011.

[7] N. Khanna and R. D. Mathews, "Can herding improve investment decisions?” The RAND Journal of Economics, vol. 42, no. 1, pp. 150-174, 2011.

[8] N. Khanna, "Optimal contracting with moral hazard and cascading," Review of Financial Studies, vol. 11, no. 3, pp. 559-596, 1998.

[9] Z. He, "A model of dynamic compensation and capital structure," Journal of Financial Economics, vol. 100, pp. 351$366,2010$.

[10] K. Hori and H. Osano, "Managerial incentives and the role of advisors in the continuous-time agency model," Review of Financial Studies, vol. 26, no. 10, pp. 2620-2647, 2013.

[11] L. Lin, "Contractual innovation in China's venture capital market," European Business Organization Law Review, vol. 10, pp. 101-138, 2020.

[12] H. Fu, J. Yang, and Y. An, "Contracts for venture capital financing with double-sided moral hazard," Small Business Economics, vol. 53, no. 1, pp. 129-144, 2019.

[13] A. An and J. Schneider, "Minimum return guarantees, investment caps, and investment flexibility," Review of Derivatives Research, vol. 19, 2015.

[14] S. Chernenko, J. Lerner, and Y. Zeng, "Mutual funds as venture capitalists? Evidence from unicorns," SSRN Electronic Journal, vol. 10, pp. 21-39, 2017.

[15] J. Burchardt, U. Hommel, and D. Kamuriwo, "Venture capital contracting in theory and practice: implications for entrepreneurship research," Entrepreneurship Theory and Practice, vol. 40, no. 1 , pp. 25-48, 2018. 